\title{
Organizations towards Best and Better Practices, SLAs and Certifications
}

\author{
Laura Prada, Henry H. Flantrmsky, and Hernán Porras
}

\begin{abstract}
In this paper we present the results of an investigation that was made about the certifications and best and better practices that exists on the field of technology. This paper shows the analysis and helps define which is one of the possible paths to follow in other to best adapt to the specific goals and needs of the group of investigation Geomática gestion y optimización de sistemas, in his purpose of providing services based on cloud computing, to public entities. Also the legal content is presented by the SLA that is a contract signed between the service provider and the service consumer.
\end{abstract}

Index Terms-Best and better practices, business model, certification, cloud computing, SLA.

\section{INTRODUCTION}

The need of being a certified organization is generated by the search of trustfulness and recognition of their potential clients; in addition by achieving this purpose, the organization is improving their organizational skills by standardizing their internal processes.

Given that the government organizations must compete for the same clients of private companies; public universities have the need to ensure the quality of the product and thus more ensure the credibility in the community, for that reason the start-up certification processes can accomplish this goal, by making the certification a way to keep up with the other organizations in the market.

The investigation group Geomática, gestión y optimización de sistemas, as a part of the University Industrial de Santander, is aiming to standardize the processes in its projects of extension. A goal that the group has is to start offering the cloud computing service to government entities, and due to the sensitivity of the information handled in these entities, it is very important to have certifications or models of best/better practices implemented that assure that the information given, is being kept safe and secure, so the clients feel trusted.

The model that the group wants to follow is on the Fig. 1, which starts from a private cloud, built to handle private services and a specific IT infrastructure, here is where all the sensitive information is going to be kept, and expands to a public cloud from which all the services like web map viewing, project oversight, among others, are going to be provided to all of the government entities and in the future to more organizations.

Manuscript received November 5, 2012; revised December 30, 2012

The authors are with the research group Geomática Gestión y Optimización de Sistemas Universidad Industrial de Santander, Bucaramanga, Santander COLOMBIA (e-mail: lorapradav@gmail.com, hflantrmsky@gmail.com, hporras2004@yahoo.com).

\section{Best AND Better Practices}

\section{A. Definition}

Best practices are methods all put in together in order to accomplish the optimization of a product or service. To achieve the goal of having a well structure procedure, for different processes, the market offers different methods, such as ITIL (Information Technology Infrastructure Library), among others.

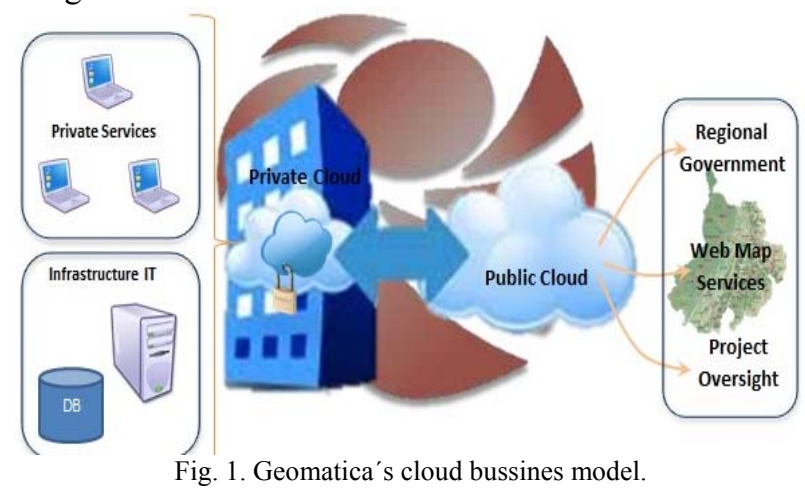

ITIL is the most widely adopted approach for IT Service Management in the world. It provides a practical, no-nonsense framework for identifying, planning, delivering and supporting IT services to the business [1].

ITIL advocates that IT services must be aligned to the needs of the business and underpin the core business processes. It provides guidance to organizations on how to use IT as a tool to facilitate business change, transformation and growth [2].

The ITIL best practices are currently detailed within five core publications which provide a systematic and professional approach to the management of IT services, enabling organizations to deliver appropriate services and continually ensure they are, meeting business goals and delivering benefits [2].

The five core guides map, figure 2, the entire ITIL Service Lifecycle, beginning with the identification of customer needs and drivers of IT requirements, through to the design and implementation of the service into operation and finally, on to the monitoring and improvement phase of the service [2].

Adopting ITIL can offer users a huge range of benefits that include:

- Improved IT services.

- Reduced costs.

- Improved customer satisfaction through a more professional approach to service delivery.

- Improved productivity.

- Improved use of skills and experience.

- Improved delivery of third party service [2]. 
It should be noted that ITIL itself is not a certification but a model that was born of a need to improve the quality of the services provided by the TI branch of the British government in the late 1980's, and became since then a guide of how to take the needs of the organization and throughout a framework of methods satisfy those needs.

Better practices, are the sequences of activities that an organization can follow to manufacture or make a product, such as, CMMI, (Capability Maturity Model Integration), among others.

CMMI models are important for improving your organization's performance and its ability to meet its business objectives. Every CMMI model has 16 core process areas. These process areas include practices that cover concepts in project management, process management, infrastructure, and support [3].

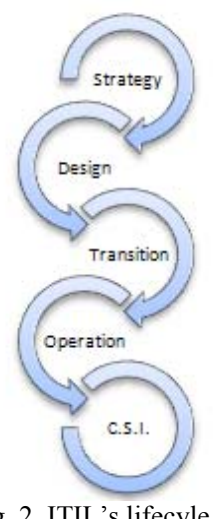

Fig. 2. ITIL's lifecyle.

\section{B. Types}

The Table I relates the best and better practices mentioned.

As said before, ITIL is a best practice, which is a guideline of concepts and practices for the management, development and operations of the information technology services. ITIL, gives detailed descriptions of an extended list of management procedures ideal to help the organizations achieve quality and efficiency on the TI operations, including the services provided.

The service lifecycle according to ITIL has 5 phases: Strategy, Design, Transition, Operation and Continuously service improvement (CSI), figure 2.

The first phase of the service lifecycle is strategy and the objective here is to define how to give value to the service provided. A way to accomplish this task is to answer two questions: What services ought to be offered to the public?, to answer this question the TI department must brainstorm and create a bank of ideas of services to provide so they have a place from where they develop more services in the future, and Why those services?. This last question must be approach from both the client's point of view and the market's point of view. This phase is the axis and base in which the rest of the phases are supported on. If the base is strong and well-structured the rest of the phases and steps that comes next are going to be on the right path to fulfill the main objective of adding value to the service.

Design, is where the new services or modifications to the ones already being offered are designed; in order to keep bringing new and optimized services to the market. In this phase, the ideas that were developed on strategy are being structured. Here is where a prototype of the service born from one of those ideas, is done. Also, both the capacities and the resources of the organization are being evaluated, in order to verify that they are at the very best performance possible.
Transition, in this phase the prototype that was made on design is being tested on a controlled testing environment. Through a check list which the IT department can make during the design phase, this list provides all the requirements the client wants the service to have, the IT department can verify how many of those requirements are being satisfied and how many are left. By doing this the quality standards are being verified. Another important characteristic of this phase is that the organization minimizes failures; all this is being done in the reproduction and trial environment. The benefit of minimizing the failures in this phase is that once the service is being executed there are going to be a very small percentage of failures to be adjusted.

\begin{tabular}{|l|l|l|}
\hline \multicolumn{2}{|c|}{ TABLE I: BEST AND BETTER PRACTICES } \\
$\begin{array}{l}\text { Best and } \\
\text { Practices }\end{array}$ & What does it certifies & $\begin{array}{l}\text { Type of } \\
\text { Certification }\end{array}$ \\
\hline ITIL & $\begin{array}{l}\text { Information Technology } \\
\text { Infrastructure Library. }\end{array}$ & Person \\
\hline CMMI & $\begin{array}{l}\text { Capability maturity model } \\
\text { integration. }\end{array}$ & N.A. \\
\hline
\end{tabular}

Operation, the objective in this phase is to coordinate and execute the activities and processes needed to deliver the service and give support to the client. During this process the small percentage of failures are being adjusted and revised. Furthermore, the technological infrastructure is being managed in order to provide the best service possible. The balance between stability and capacity is achieved in this phase, in order to deliver the most efficient, valuable and productive service to the client.

Continuously service improvement, this phase is present in all of the other phases making sure that all the objectives are well executed and all the steps completed. In strategy, is present in the moment of assuring the well-structured base of the lifecycle. During Design, when the prototype is made by the requirements of the client. In Transition, when the prototype is evaluated for the best performance and fulfilling the client's requirements. Throughout Operation, when the IT department is synchronizing with the client the delivery of the service. The objective of this phase is to guarantee the return of the investment done in the development of the service, the support of the processes and maintaining the efficiency in all al the life cycle of the service.

ITIL also provides the organization with a guide to establish processes, roles and functions. These 3 items are very important in the administration of an organization, because they help the IT department in handing over the responsibilities to each person. Doing this improve the efficiency of the organization, because each role has its own set of responsibilities and can focus on complying them. The time is better spent and the people are being more productive.

A process is a well structure group of activities designed with the goal of accomplishing a specific objective of the organization.

A role is a set of responsibilities defined in a process and are assigned to a person or a team.

A function is a group of people and the tools that they use to make one or more processes or activities. 
Today most of the organizations are applying the concept of time to market, which is to do more with less, by which one person can be assigned with the activities of a two-person job[4].

Meanwhile, CMMI is a process improvement approach that provides organizations with the essential elements of effective processes, which will improve their performance [5].

TABLE II: COMPLEMENT OF THE ISO, BEST AND BETTER PRACTICES

\begin{tabular}{|l|c|l|l|l|}
\hline $\begin{array}{l}\text { Standard/ } \\
\text { best and } \\
\text { better } \\
\text { Practice }\end{array}$ & $\begin{array}{l}\text { Information } \\
\text { Security }\end{array}$ & $\begin{array}{l}\text { Evaluation of } \\
\text { the } \\
\text { improvements }\end{array}$ & $\begin{array}{l}\text { How } \\
\text { To } \\
\text { Guide }\end{array}$ & $\begin{array}{l}\text { What } \\
\text { to do } \\
\text { Guid } \\
\text { e }\end{array}$ \\
\hline ISO 20000 & $\mathrm{X}$ & & & \\
\hline ITIL & $\mathrm{X}$ & & $\mathrm{X}$ & \\
\hline CMMI & & $\mathrm{X}$ & & $\mathrm{X}$ \\
\hline
\end{tabular}

Regarding the certification, CMMI does not give a certificate to the organization nor the staff. CMMI uses an evaluation method called SCAMPI, (Standard CMMI Appraisal Method for Process Improvement), to give a qualification of the level of maturity to the processes implemented in the organization. This evaluation helps the organization to identify their weaknesses and strengths and focus on transforming the weaknesses into strengths, and improve them.

The Levels of SCAMPI are: initial, managed, defined, quantitatively managed and optimizing.

The first level, has more risk than productivity, the organizations that are ranked in this level are organizations that doesn't have any organization at all and are poorly controlled and most of them reactive.

In the second level, are those that have characterized processes for projects and are managed. Usually some of the organizations starts on level two, because they have defined some processes and have control on some of them.

The organizations ranked on level three, are those that begin to be more productive and minimize the risk.

On the fourth level, the processes executed in the organizations are measured and controlled in a quantitatively form.

And finally, when an organization reaches the fifth level, their productive and quality of the processes is in the verge and the only thing to do once the organization has achieve this point, is to focus on the continuous improvement of the process, in order to keep optimizing the processes and with this the services that the organization provides to their clients. Also in this level the risk is on its minimal percentage.

The following table show how, implementing the ISO standards complemented with ITIL and CMMI, can be used as a help to build a better front since all of them can be applied at the same time in the organization and does not exclude one another. By implementing all of them, the organization can assure that has covered all of the bases, and fulfill the gaps the other standard or best and better practice have.

\section{Service LeVEl AgreEment}

A Service Level Agreement, SLA, is a document that includes a description of the agreed service, service level parameters, guarantees and actions and remedies for all cases of violations [6].

This part of the service contract is where all the levels of the service are defined, so it is clear which responsibilities are from the service provider and which are from the service consumer, this is done in order to make the process as transparent as it can be.

The SLA must be as clear and specific, about the service and its phases, so there are not confusions and like all legal documents, it has its own terms in order to describe the quality, security, privacy, connectivity, scalability, availability and methods for cost calculation, of the service from the client. The following are some of the requirements that the SLA include when is about a web service:

- The format must clearly describe the service so that the service consumer can easily understand the operation of the services.

- Present the level of the performance of the service.

- Define ways by which the service parameter can be monitored and the format of monitoring reports.

- Penalties when service requirements are not met.

- Present the business metrics such as billing and stipulate when this service can be terminated without any penalties being incurred[7].

When the service provider includes services on cloud, such as Infrastructure as a Service, IaaS, which is the case of this investigation group, there are some more requirements to add to the SLA, these are known as non-functional requirements:

- Security and privacy, in this requirement, the service provider must ensure the client the information is traveling through secure channels.

- Scalability, because having information on the cloud, the client pay as he uses, meaning the client only pays as he uses the service. With this requirement the service provider is offering the client the possibility to scaling up or down as he requires.

- Availability, means, that the service must be up and running all the time. Although the service provider specifies this requirement in percentage, for example, the service provider ensures the client that the service never goes under $95 \%$ of online performance.

- Method for cost calculation, because this is a cloud based service, it is pay as you use, so the cost of the service is based upon, time, size and transfers done in a specific amount of time. Another method could be by the amount of users.

- Configuration of the service, due to be in the cloud, the service consumer does not have to be the one setting up the service, this is the service provider responsibility as the configuration of the virtual machines the service is running on. Some of the parameters the service provider must take into consideration are: the virtual machine must be ready to be used at any time, the CPU must provide the virtual machine with the velocity necessary to support the service, the storage size of the data is agreed with the service consumer, among others.

\section{PRoposal - CONCLUSION}

Taking into consideration that an organization with intention of becoming a cloud service provider should start by implementing either a certification or a model of best and better practice for management procedures, and in respond to the group's need, to become a cloud service provider, a proposal was draft for the optimization of the technological infrastructure following a best practice model. This can be 
achieved by using the new technologies to develop a private cloud infrastructure that help the group to provide new services in the cloud to the regional government.

In this case, the organization should start by implement ITIL, because it is a well detailed model that from the creation of the service is involved in all of its steps.

Also, the organization must have a well written SLA, in order to deliver and ensures an excellent service in order to have satisfied and well served service consumers.

And along the time, once they have controlled and characterized the processes, they can evaluate the maturity with SCAMPI and get ranked on CMMI and from there continue to improve the processes so they can optimize the services provided.

And finally, the organization should be certified on the ISOs, being the first of them the 9001:2008, to guarantee the quality of the information that is handled. As shown in the Fig. 3.

\section{$\mathrm{ITIL}>\mathrm{SLA}>\mathrm{CMMI}>$ CERTIFICATIONS}

Fig. 3. Ideal process overview.
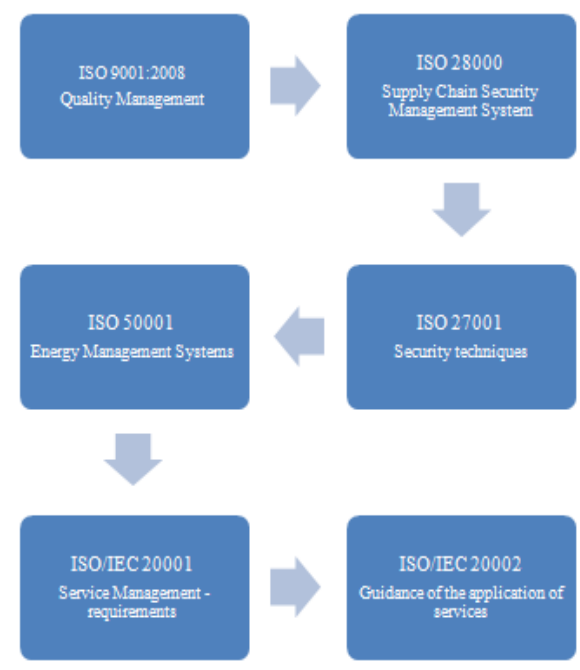

Fig. 4. Proposed Methodology for the implementation of the certifications.

Then the organization should get certified on ISO 28000 , Supply Chain Security Management System, which assures the security on every point that the information makes a stop.

The thrid certification that must be implemented is the ISO 27001, Information technology - Security techniques Information security management systems - Requirements. The name already says the reason why the organization should continue with this certification, simply because it is about the implementation of techniques for the security of the information.

This can help the organization to gain the trust of the client, who needs to be certain that the information that is being given to keep storage is not going to be used by third parties without their knowledge.

Having assured the security of the information, on two angles, the first is the nodes trough where it travels and the second one is the form the information is being stored.

The organization can continue with the process of getting more certifications, the order could be: ISO 50001, ISO/IEC 20000 part 1 and part 2, as shown in the Fig. 4.

\section{ACKNOWLEDGMENT}

Thanks to the investigation group Geomática gestión $y$ optimización de sistemas, who finances this project and provides a platform to expand the knowledge of all of the people that works in the group.

\section{REFERENCES}

[1] Certification. [Online]. Available: http://www.icontec.org.co/index.php?section=535\&module=navigatio nmodule

[2] What is [Online]. Available: http://www.itil-officialsite.com/AboutITIL/WhatisITIL.aspx

[3] ITIL: Overview and benefits. [Online]. Available: http://www.itil-officialsite.com/AboutITIL/WhatisITIL.aspx

[4] TSO (The Stationery Office), ITIL 3 Official Introduction, Crown Copyright, 2007.

[5] Overview. [Online]. Available: http://www.sei.cmu.edu/cmmi/

[6] A. Andrieux et al., Web services agreement specification (WS-Agreement). 2004.

[7] M. Alhamad, T. Dilon, and E. Chang, "Conceptual SLA framework for cloud computing," in Proc of 4th IEEE International Conference on Digital Ecosystems and Techonologies, 2010, pp 606-610.

[8] L. Ballesteros, "Towards a methodology to define Service Level Agreemets in a convergent network scenario" IEEE Andescon, 2010.

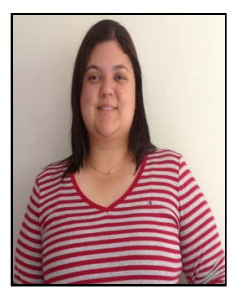

Laura Alejandra Prada Vesga was born in Colombia, on March 11th, 1985. Graduated from Colegio La Quinta del Puente, in 2002. Started to study in Universidad Industrial de Santander, located in Bucaramanga, on 2003 and graduate on 2009, mayored in Systems Engineering. Laura is certified on ITIL v3.0 fundaments, and she worked in the División editorial y publicaciones until 2010, located in the Universidad Industrial de Santander, as a systems engineer. Then she start working in the Geomática, Gestión y Optimización de Sistemas research group, as a systems engineer and now she is manager IT. She is interested in the certification processes and how to implement them in the group. Ing. Laura Alejandra Prada Vesga, was part of the logistics committee of the ler Festival de Cultura Libre that took place in the University Industrial de Santander, on 2012.

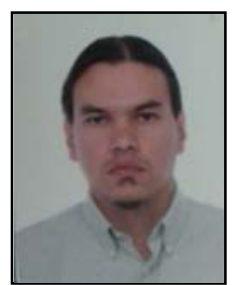

Henry H. Flantrmsky was born in Bucaramanga, colombia, on July 29th, 1980. With a degree in philosophy from Universidad industrial de Santander, Bucaramanga, Colombia in 2008 and a master degree in logic and philosophy of science from Universidad de Salamanca, Salamanca, España in 2011. Right now he is working in his $\mathrm{Ph}$. D. thesis to obtain the doctorate degree also in logic and philosophy of since with Universidad de Salamanca. Henry has worked in the philosophy faculty as assistent professor and right now is working in the Geomática, Gestión y optimización de Sistemas research group of the Universidad Industrial de Santander as coordinator in the Cloud Computing project of the group. He has published the paper La Computación en Nube y el cambio del Paradigma Informático in the journal Pensamiento y Cultura, Bogotá: Universidad de la Sabana, 2011. He is interested in the problems of philosophy, technology and society.

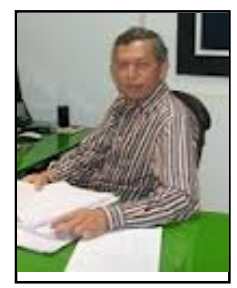

Hernán Porras Díaz was born in Bucaramanga, Colombia, on September 24th, 1955. With a degree in civil engineer from Universidad industrial de Santander, Bucaramanga, Colombia in 1981 and a master degree in Informatica from Universidad Politecnica of Madrid, in 1986, a Ph. D. in Ingenieria Telematica from Universidad Politecnica de Madrid, 1987, and another master degree in Gestion Tecnologica from the Universidad Pontificia Bolivariana, Colombia, 1994. Hernán is the director of the Geomática, Gestión y optimización de Sistemas research group of the Universidad Industrial de Santander, he also is a professor of the Civil engineer faculty since 1987 . He is an experienced professional on topics related to transport operation and planning and regional development. He was the in charge of the massive transportation studies in Bucaramanga. He was the Environment and Water Secretary of Santander department, director of the Administrative Department of Municipal Planning in Bucaramanga, chief of the planning office in Universidad Industrial de Santander, among other administrative positions. 